\title{
Silício na mitigação de estresse causado pela falta ou excesso de nitrogênio em alface
}

Para o bom rendimento de espécies cultivadas, em especial a alface que é uma das mais importantes folhosas para consumo in natura, um dos principais fatores que afetam seu desempenho no campo é a falta de nutrição adequada para a cultura. Com isso, a busca por informações sobre a indisponibilização ou disponibilização de nutrientes para essa espécie, considerada sensível, passa a ser uma importante prática para entender a dinâmica na resposta da cultura submetida à presença ou ausência de nutrientes, como buscado nessa pesquisa utilizando o silício. Objetivou-se avaliar os efeitos do silício em alface cultivada em solução nutritiva, sob estresse causado pela falta ou excesso de nitrogênio. $O$ experimento foi conduzido em delineamento experimental inteiramente casualizado, em esquema fatorial $3 \times 2$ com três repetições. Os fatores foram formas de $\mathrm{N}$ (N-30\% na forma de NO3-; N-100\% na forma de NH4+ e N-100\% na forma de NO3-) na presença e ausência de silício ( $56 \mathrm{mg}$ de Si L-1). Avaliou-se índice de cor verde, massa fresca total, massa fresca comercial, massa seca aérea e da raiz, índice comercial, comprimento do caule, diâmetro da cabeça, número total de folhas e número de folhas comerciais. Utilizar $100 \%$ de $\mathrm{N}$ na forma de NH4+ reduz a produtividade da alface, evidenciando que o fornecimento total do $\mathrm{N}$ na forma amoniacal é toxico a planta.

\section{Silicon in the stress mitigation caused by the lack or excess of nitrogen in lettuce}

\begin{abstract}
For the good yield of cultivated species, especially lettuce, which is one of the most important leafy vegetables for fresh consumption, one of the main factors that affect its performance in the field is the lack of adequate nutrition for the crop. Thus, the search for information about the unavailability or availability of nutrients for this species, considered sensitive, becomes an important practice to understand the dynamics in the response of the culture submitted to the presence or absence of some nutrients, as sought in our research using silicon. The objective was to evaluate the effects of silicon on lettuce grown in nutrient solution, under stress caused by the lack or excess of nitrogen. The experiment was conducted in a completely randomized design, in a $3 \times 2$ factorial scheme with three replications. The factors were forms of $\mathrm{N}(\mathrm{N}-30 \%$ in the form of NO3-; $\mathrm{N}-100 \%$ in the form of $\mathrm{NH} 4+$ and $\mathrm{N}-100 \%$ in the form of NO3-) in the presence and absence of silicon (56 $\mathrm{mg} \mathrm{Si} \mathrm{L-1} \mathrm{).} \mathrm{Green} \mathrm{color} \mathrm{index,} \mathrm{total} \mathrm{fresh} \mathrm{weight,} \mathrm{commercial} \mathrm{fresh} \mathrm{weight,} \mathrm{aerial} \mathrm{and} \mathrm{root} \mathrm{dry} \mathrm{weight,} \mathrm{commercial} \mathrm{index,} \mathrm{stem} \mathrm{length,} \mathrm{head} \mathrm{diameter,} \mathrm{total} \mathrm{number}$ of leaves and number of commercial leaves were evaluated. Using $100 \% \mathrm{~N}$ in the form of $\mathrm{NH} 4+$ reduces the productivity of lettuce, showing that the total supply of $\mathrm{N}$ in ammoniacal form is toxic to the plant.
\end{abstract}

Keywords: Lactuca sativa L.; Horticulture; Beneficial element; Nitrogen fertilization.

\section{Topic: Ciências do Solo}

Reviewed anonymously in the process of blind peer.
Received: 02/10/2020

Approved: 20/11/2020
Aureane Cristina Teixeira Ferreira Cândido (DD Universidade Federal do Oeste do Pará, Brasil http://lattes.cnpq.br/3249825697224083 http://orcid.org/0000-0001-7540-1325 aurianeferreira@hotmail.com

Adriano Maltezo da Rocha (i)

Universidade do Estado de Mato Grosso, Brasil http://lattes.cnpq.br/0322584934720610

http://orcid.org/0000-0002-0032-0034 admr.maltezo@hotmail.com

\section{Henildo de Sousa Pereira (iD}

Universidade do Estado de Mato Grosso, Brasil http://lattes.cnpq.br/9233835142700599

http://orcid.org/0000-0002-1297-8183 enildop@gmail.com

\author{
Simone Hemkemeier Lourini (iD) \\ Universidade do Estado de Mato Grosso, Brasil \\ http://lattes.cnpq.br/7069580799474692 \\ http://orcid.org/0000-0003-0399-0364 \\ si.hemkemeier@gmail.com \\ Gustavo Caione (it) \\ Universidade do Estado de Mato Grosso, Brasil \\ http://lattes.cnpq.br/8169632591906614 \\ http://orcid.org/0000-0002-6728-8008 \\ gcaione@unemat.br
}

\section{Referencing this:}

CÂNDIDO, A. C. T. F.; ROCHA, A. M.; PEREIRA, H. S.; LOURINI, S. H.; CAIONE, G.. Silício na mitigação de estresse causado pela falta ou excesso de nitrogênio em alface. Revista Ibero Americana de Ciências Ambientais, v.11, n.6, p.23-32, 2020. DOI:

http://doi.org/10.6008/CBPC2179-6858.2020.006.0003 


\section{INTRODUÇÃO}

Dentre as hortaliças, a alface (Lactuca sativa L.) é uma das folhosas mais consumidas em todo mundo, pois, além de ter ampla aceitação cultural, é uma espécie que pode ser produzida durante o ano todo, em diferentes condições ambientais e climáticas (ABCSEM, 2017). A produção mundial, no ano de 2017, atingiu o equivalente a 26,9 milhões de toneladas, cultivadas numa área de 1,2 milhões de hectares (FAO, 2019).

Constantemente, em ambiente natural, as plantas cultivadas passam por diversas situações de estresses, como oscilações de temperatura, umidade, radiação solar, ataque de pragas ou patógenos, dentre outros, e conseguem modular respostas de defesa de forma a superar tais estresses e retornar ao metabolismo normal (DEUNER et al., 2015).

O silício (Si) é estudado pelo fato de minimizar os estresses de diferentes naturezas e proporcionar melhor aproveitamento de alguns nutrientes pelas plantas, especialmente o nitrogênio (MALAVOLTA, 2006). O Si é o segundo elemento com maior abundância na crosta terrestre (MA et al., 2006a), e é caracterizado como elemento benéfico. Ele vem demonstrando que na nutrição de plantas poderá contribuir de forma significativa para a agricultura por possibilitar inúmeros benefícios, possibilitando um incremento na produtividade de diversas culturas agrícolas, podendo apresentar efeitos benéficos no crescimento, desenvolvimento e produtividade da cultura (LIMA FILHO et al., 2007). Além disso, o Si pode mitigar os efeitos do déficit hídrico nas plantas e aumentar a eficiência do uso da água, além de promover melhorias nas vias metabólicas, resultando em adaptações às mudanças ambientais (ZHANG et al., 2017).

A deposição de Si ocorre em diferentes partes da planta, como a epiderme da parte aérea, e contribui efetivamente para o aumento da absorção de nutrientes, modificação do mecanismo de troca gasosa, aumento do sistema de defesa antioxidante, modificação de osmólitos e fitohormônios, além de atuar diretamente na redução da transpiração por meio de sua deposição no apoplasto foliar (ZHANG et al., 2017).

Já o nitrogênio $(\mathrm{N})$ é crucial no metabolismo das plantas, participa como constituinte de proteínas, coenzimas, ácidos nucleicos, clorofila e enzimas, além de controlar o desenvolvimento das plantas (ABRANTES et al., 2010), sendo então esses processos totalmente afetados na falta desse nutriente.

A fim de alcançar um crescimento eficiente, desenvolvimento e reprodução, as plantas necessitam de adequadas quantidades de nitrogênio. $O$ uso de altas concentrações desse nutriente aumenta o ciclo vegetativo das plantas proporcionando menor armazenamento de carboidratos, deixando os tecidos das plantas mais tenros, aumenta o auto-sombreamento e a incidência de acamamento, e, em alguns casos, pode atrasar a floração, ocorrendo maior consumo de energia nos processos de absorção e de assimilação de nitrato (MALAVOLTA, 2006; SCHRADER, 2015).

Entretanto, apesar da importância do suprimento de $\mathrm{N}$ para as plantas, ainda existem dúvidas sobre a relação ótima de amônio e nitrato no meio de cultivo (SILVA JÚNIOR, 2015). O excesso de nitrogênio pode ser tóxico às plantas e induzir a deficiência ou reduzir a absorção de outros nutrientes (SALVADOR et al., 1999).

O Si pode auxiliar as plantas quando estas são expostas a situações adversas, sendo assim, surge à 
hipótese que o Si poderá ser mitigador dos efeitos causados por falta ou excesso de N. Deste modo, objetivou-se avaliar os efeitos do silício em alface cultivada em solução nutritiva, sob situação de estresse causado pela falta ou excesso de nitrogênio.

\section{MATERIAIS E MÉTODOS}

O experimento foi conduzido em casa de vegetação não climatizada localizado na área experimental da Universidade do Estado de Mato Grosso, entre os dias 15 de maio ao dia 25 de junho do ano de 2016.

Para a pesquisa, foram utilizadas mudas de alface tipo Americana, produzidas em espumas fenólicas com dimensões de $2 \times 2 \times 2 \mathrm{~cm}$, contendo uma planta por célula. Aos 15 dias após a germinação, as mudas foram transplantadas para recipientes com volume de 7 litros de solução nutritiva padrão, onde o silício foi adicionado nos tratamentos $+\mathrm{Si}$ e permaneceram por 12 dias (período reservado para as plantas absorverem o Si) na solução proposta por Hoagland et al. (1950). Passado este período, realizou-se a aplicação dos tratamentos com o nitrogênio. Em toda a condução do experimento o pH da solução foi aferido duas vezes ao dia.

O delineamento experimental utilizado foi inteiramente casualizado, arranjados em esquema fatorial $3 \times 2$, com três repetições. Os fatores foram as formas de nitrogênio, sendo um tratamento com $30 \%$ do nitrogênio total (deficiência) na forma de nitrato $\left(\mathrm{N}-30 \%\right.$ em $\left.\mathrm{NO}_{3}{ }^{-}\right)$; segundo tratamento com a aplicação de 100\% de nitrogênio (excesso) na forma de amônio ( $\mathrm{N}-100 \%$ em $\mathrm{NH}_{4}{ }^{+}$) e outro com a aplicação de $100 \%$ do nitrogênio (completo) na forma de nitrato ( $\mathrm{N}-100 \%$ na forma de $\mathrm{NO}_{3}{ }^{-}$) na presença e ausência de silício, sendo esse aplicado na proporção de $56 \mathrm{mg}$ de Si $\mathrm{L}^{-1}$ da solução.

Após 25 dias, foram realizadas as avaliações em 4 plantas escolhidas aleatoriamente de cada repetição, que foram lavadas em água corrente para remover todo resíduo. As variáveis avaliadas foram índice de cor verde (ICV), massa fresca total (MFT), massa fresca comercial (MFC), massa seca aérea (MSA) e massa seca radicular (MSR), índice comercial (IC), comprimento do caule (CC), diâmetro da cabeça de cada planta (DC), número de folhas totais (NFT) e número de folhas comerciais (NFC).

O índice de cor verde foi mensurado utilizando o aparelho modelo SPAD-502, analisando as folhas intermediárias, sendo coletados 10 pontos aleatórios em cada folha e amostradas quatro folhas por planta para obtenção da média. Para massa seca total e massa seca comercial, foram obtidas as massas das cabeças, com e sem o descarte das folhas não comerciais, mensurando com auxílio de uma balança analítica de precisão.

As respectivas massas seca, aérea e radicular, foram obtidas após a secção e corte transversal do coleto de cada planta, destacando a parte aérea e radicular, sendo nesse momento obtidos os dados do comprimento do caule com auxílio de um paquímetro digital, e após isso, feito a secagem até atingir massa constante, em estufa de circulação de ar forçada, regulada para 65 e posterior mensuração.

Para o número de folhas totais, foram contadas todas as folhas desenvolvidas em cada planta, sem levar em conta seu aspecto visual e comercial. Enquanto que para a determinação do número de folhas comerciais, foram contadas todas as folhas, exceto as depreciadas que não apresentavam aspectos aceitáveis 
para o mercado.

A variável diâmetro da cabeça foi obtida com auxílio de uma régua graduada, medindo o diâmetro de toda a cabeça da alface, sendo por fim, determinado o índice comercial (equação 1):

$$
I C=\frac{M F T}{M F C} \quad(\text { Equação } 1)
$$

$\mathrm{IC}=$ índice comercial, MFT = massa fresca total, MFC = massa fresca comercial.

Após obtenção dos resultados, foram feitas análises de homocedasticidade das variâncias, e suas médias comparadas pelo teste de Tukey a $5 \%$ de probabilidade com auxílio do programa estatístico SISVAR ${ }^{\circ}$ (FERREIRA, 2011).

\section{RESULTADOS E DISCUSSÃO}

As variáveis MFT, MFC, MSA, MSR e IC, apresentaram resposta de influência apenas para o fator nitrogênio (N) de maneira isolada. Observando-se que o silício, tanto de forma isolada como em interação com o nitrogênio, interferiu na variável ICV, como observado na Tabela 1. Esse fato pode estar relacionado a capacidade do silício em mitigar os efeitos causados pela falta ou excesso de $\mathrm{N}$, um dos principais elementos essenciais para o desenvolvimento de plantas. Para alguns autores a presença do silício é de grande relevância no desenvolvimento bioquímico e na fisiologia da planta, com isso, a não influência encontrada para as variáveis como acúmulo de massa pode ser reflexo da sua funcionalidade no benefício nutricional das plantas, pois Heckman (2013) e Fátima et al. (2019) apresentam que o silício tem uma notável importância nos aspectos que envolvem a lignificação e enrijecimento da parede. Entretanto, isso não significa que, com maior lignificação e outros aspectos bioquímicos afetados, haveria alguma influência no incremento de massa.

Tabela 1: Índice de cor verde - ICV, massa fresca total - MFT, massa fresca comercial - MFC, massa seca aérea - MSA, massa seca raiz - MSR e índice comercial - IC da alface cultivada em solução nutritiva em função do silício e formas de nitrogênio. Alta Floresta-MT, 2016

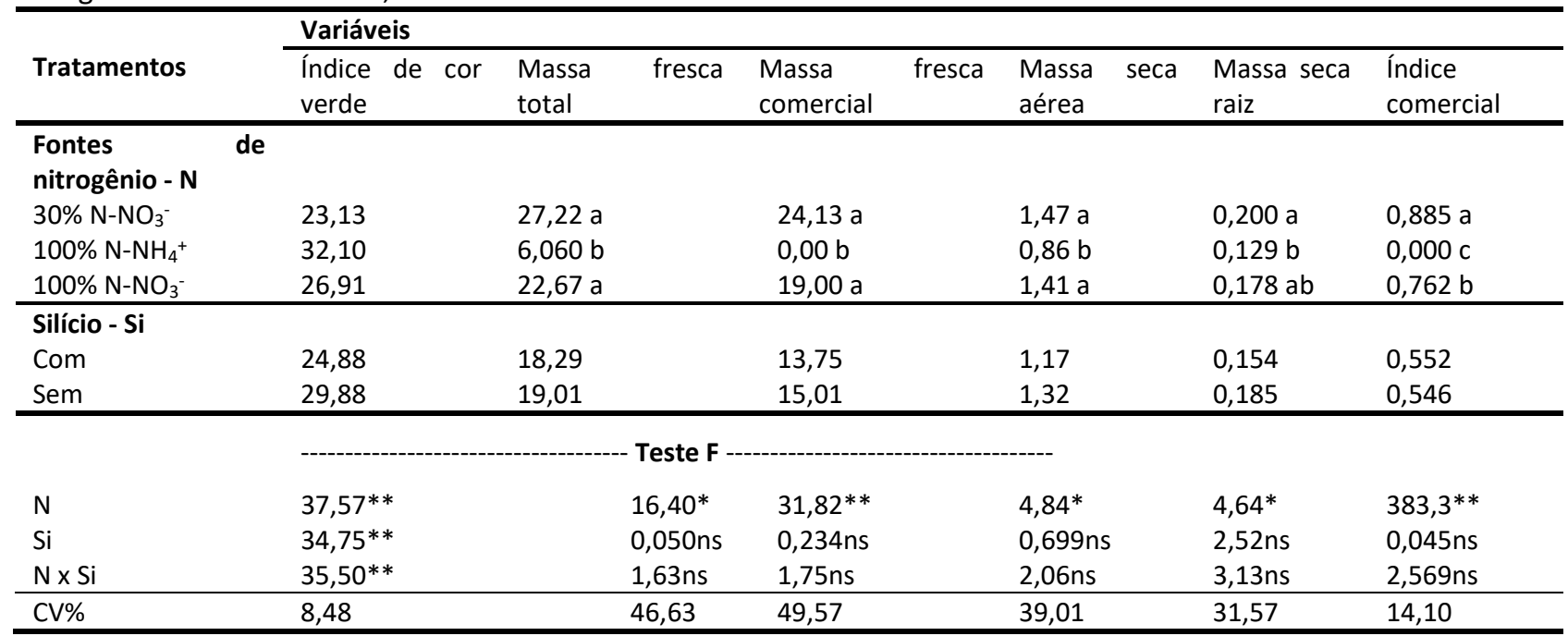

Médias seguidas de mesma letra na coluna, não diferem entre si, pelo teste de Tukey a $5 \%$ de probabilidade. Teste $\mathrm{F}-$ ns, * e ** - não significativo e significativo a $5 \%$ e $1 \%$ de probabilidade de erro.

Quanto à avaliação das médias das variáveis que não sofreram a influência do silício, nota-se que o fornecimento de $\mathrm{N}\left(\mathrm{N}-100 \% \mathrm{NH}^{+4}\right)$ em excesso, foi o fator determinante para o decréscimo daquelas 
diretamente relacionadas a parte aérea (MFT, MFC, MSA e IC). Isso demonstra que a relação de excesso de nitrogênio é observada de maneira notória no desenvolvimento vegetativo das plantas em estudo, pois, segundo Aguiar Júnior et al. (2010) e Guimarães et al. (2019), o N é um elemento indispensável para espécies folhosas, pois age na síntese de alguns aminoácidos essenciais e por consequência para a síntese da molécula de clorofila, melhorando vigor, crescimento da parte aérea, desenvolvimento vegetativo, índice de cor verde e produção. Entretanto, possivelmente, o excesso desse elemento fez com que houvesse um distúrbio fisiológico que afetou nitidamente o incremento para variáveis em estudo.

Já para a ínfera dose de $30 \%$ de $\mathrm{N}$ na forma de $\mathrm{NO}_{3}{ }^{-}$, não houve diferença significativa quando comparado com o $\mathrm{N}$ completo, $100 \%$ do $\mathrm{N}$ na forma de $\mathrm{NO}_{3}{ }^{-}$, exceto para o índice comercial. Isto acontece por que as plantas conseguem assimilar o que está disponível, ou seja, mesmo que os $30 \%$ de $\mathrm{Nem} \mathrm{NO}_{3}{ }^{-}$ sejam inferiores ao necessário, estes estavam na forma adequada, facilitando a síntese pelas plantas, sem necessidade de nenhuma transformação do $\mathrm{N}$.

Observando as variáveis individualmente, a massa fresca total apresentou maior valor quando a fonte de nitrogênio utilizada foi $\mathrm{NO}_{3}{ }^{-}$, independentemente dos teores de $\mathrm{N}$ aplicados, já quando o $\mathrm{N}$ foi aplicado na forma de $\mathrm{NH}_{4}{ }^{+}$, houve redução drástica. Isso ocorre porque, para muitas plantas de interesse agrícola, a preferência na nutrição está na forma nítrica e não amoniacal e, possivelmente, o excesso de $\mathrm{N}$ na forma amoniacal atuou prejudicialmente no desempenho desta variável. Confirmando os resultados, autores como Chen et al. (2009), avaliando soja no período vegetativo, observaram que estas aos 20 dias não diferiram quanto as concentrações de $\mathrm{NO}_{3}{ }^{-}$, houve diferença apenas quando se fez uso de $\mathrm{N}$ na forma de $\mathrm{NH}_{4}{ }^{+}$. Essa redução pode ser atribuída ao fato das plantas precisarem de mais carboidratos para assimilação e desintoxicação causado pelo $\mathrm{NH}_{4}{ }^{+}$(NATHAWAT et al., 2007), ou também pelo desequilíbrio hormonal e uma queda de citocininas na seiva do xilema o que acarreta uma redução de crescimento (WALCH-LIU et al., 2000).

A massa fresca comercial foi semelhante à massa fresca total, no entanto, o tratamento $100 \%$ de $\mathrm{N}$ na forma de $\mathrm{NH}_{4}^{+}$não produziu folhas com padrões comerciais. De acordo com a literatura isso ocorre pela necessidade de um maior gasto de energia quando se utiliza $\mathrm{N}$ na forma $\mathrm{NH}_{4}{ }^{+}$, assim as folhas não tiveram um desenvolvimento no padrão comercial, pois a energia utilizada para o desenvolvimento celular é reduzida (BRITO et al., 2001).

Esses resultados atestam que o $\mathrm{NH}_{4}{ }^{+}$foram mais prejudiciais à expansão que ao aparecimento das folhas, em semelhança ao que foi observado por Raab et al. (1994). Esse efeito do amônio sobre a expansão foliar tem sido relacionado à alteração negativa provocada no potencial hídrico foliar em função da maior resistência hidráulica das raízes (ADLER et al., 1996), à menor translocação de citocininas das raízes para a parte aérea (WALCH-LIU et al., 2000) e à menor absorção de cátions (RAAB et al., 1995). Confirmando também os resultados semelhantes observados para massa seca aérea, que quando utilizou $100 \%$ do N na forma de $\mathrm{NH}_{4}{ }^{+}$, se obteve novamente os menores incrementos.

Em adição aos resultados do não incremento da massa aérea que tem influência direta na produtividade da alface, autores como Campos et al. (2016), avaliando plantas de pepino, observaram que quando se utilizou o $\mathrm{N}$ na forma amoniacal houve uma redução de produção, sendo essa redução de massa 
seca atribuída ao fato do excesso de $\mathrm{N}$ causar toxicidade as plantas.

Para o IC, novamente observa-se que o $\mathrm{N}$ em excesso na forma de $\mathrm{NH}^{+}{ }_{4}$ ocasionou decréscimo. Tratase de uma variável importante, visto que indica se determinado tratamento tem maior número de folhas com qualidade comercial, ou seja, folhas menos influenciadas por fatores indesejados. No presente trabalho as plantas nutridas com $\mathrm{N}$ na forma $\mathrm{NO}_{3}{ }^{-}$, independentemente da concentração (30\% ou $100 \%$ ), embora apresentaram diferença estatística entre si, apresentaram valores acima de 0,7 na classificação do índice comercial, sendo ambas iguais nesse quesito, já que números acima de 0,7 são considerado ideais (SANTOS et al., 2011). Porém as plantas nutridas com $\mathrm{N}$ na forma de $\mathrm{NH}_{4}{ }^{+}$tiveram o índice nulo, reflexo de não terem produzido folhas comerciais.

Ao avaliar o sistema radicular, a massa seca de raiz, mesmo apresentando valores inferiores quando o $\mathrm{N}$ utilizado estava na forma $\mathrm{NH}_{4}{ }^{+}$não diferenciou do tratamento com $\mathrm{NO}_{3}{ }^{-} 100 \%$. A maior redução do sistema radicular das plantas cultivadas exclusivamente com amônio tem sido atribuída ao fato de que os carboidratos transloucados das folhas para as raízes de absorção são utilizados, prioritariamente, como esqueletos de carbono e energia para o processo de assimilação desse íon, para evitar seu acúmulo em níveis tóxicos, e não para os processos associados ao crescimento desse órgão (LEWIS et al., 1989).

Avaliando o desdobramento da interação de N x Si para a variável ICV (Tabela 2), observa-se que na ausência de Si, houve maior resultado quando $100 \%$ do $\mathrm{N}$ foi na forma de $\mathrm{NH}_{4}{ }^{+}$(excesso), seguida da aplicação de $100 \%$ de $\mathrm{N}$ na forma de $\mathrm{NO}_{3}{ }^{-}$(completo) e depois com o valor inferior de $\mathrm{N}, 30 \%$ e na forma de $\mathrm{NO}_{3}{ }^{-}$ (deficiência). Demonstrando assim, que o silício é um elemento benéfico, interferindo nas plantas quanto à possíveis problemas relacionados com deficiência e/ou excesso de outros elementos, isso pode ser notado já que, quando o Si não estava presente, houve variabilidade entre as doses de N, proporcional à produção da molécula de clorofila conforme a maior quantidade de $\mathrm{N}$ disponível.

Tabela 2: Interações entre silício e formas de nitrogênio para Índice de cor verde-ICV de plantas de alface. Alta FlorestaMT, 2016

\begin{tabular}{cll}
\hline \multirow{2}{*}{ Fontes de Nitrogênio } & \multicolumn{2}{l}{ Silício } \\
\cline { 2 - 3 } & $-\mathrm{Si}$ & $+\mathrm{Si}$ \\
\hline $30 \% \mathrm{~N}^{-\mathrm{NO}_{3}-}$ & $22,37 \mathrm{Ac}$ & $23,90 \mathrm{Aa}$ \\
$100 \% \mathrm{~N}^{-} \mathrm{NH}_{4}^{+}$ & $39,58 \mathrm{Aa}$ & $24,63 \mathrm{Ba}$ \\
$100 \% \mathrm{~N}_{3}{ }^{-}$ & $27,71 \mathrm{Ab}$ & $26,12 \mathrm{Aa}$ \\
\hline
\end{tabular}

Médias seguidas de mesma letra minúscula na coluna e maiúscula na linha, não diferem entre si, pelo teste de Tukey a $5 \%$ de probabilidade.

Esses resultados são confirmados quando avaliado o fornecimento de $\mathrm{N}$ na presença do elemento benéfico, sendo observado um potencial atenuante, onde o excesso teve seu ICV reduzido drasticamente, sendo estatisticamente iguais quando comparado com o tratamento completo e na falta de $\mathrm{N}$.

Para as demais variáveis como NFT, NFC, DC e CC, foram observadas interação significativa entre o fornecimento de nitrogênio e silício para todas as variáveis testadas (Tabela 3).

$\mathrm{Na}$ análise do desdobramento, notou-se que na ausência de Si, o tratamento envolvendo $100 \%$ do N na forma de nitrato apresentou o menor número de folhas totais, diferenciando-se significativamente da utilização da fonte de $100 \%$ do N na forma de amônio e $30 \%$ na forma de nitrato. Porém, na presença de Si, 
o menor número de folhas se deu no tratamento de inferior, com $30 \%$ de $\mathrm{N}$ através de $\mathrm{NO}_{3}{ }^{-}$(Tabela 4).

Tabela 3: Número de folhas totais e comerciais, diâmetro da cabeça e comprimento do caule de plantas de alface cultivadas em solução nutritiva em função da presença e ausência de silício e formas de nitrogênio. Alta Floresta - MT, 2016

\begin{tabular}{lllll}
\hline \multirow{2}{*}{ Tratamentos } & \multicolumn{4}{c}{ Variáveis } \\
\cline { 2 - 5 } & № folhas totais & № folhas comerciais & Diâmetro da cabeça $(\mathrm{cm})$ & Comprimento do caule (cm) \\
\hline $\mathrm{N}$ & Teste $\mathrm{F}$ & & $49,00^{*}$ & \\
$\mathrm{Si}$ & $3,66^{*}$ & $21,84^{*}$ & $0,288 \mathrm{~ns}$ & $0,10^{*}$ \\
$\mathrm{~N} \mathrm{x} \mathrm{Si}$ & $0,011 \mathrm{~ns}$ & $104,84^{*}$ & $12,15^{*}$ & $9,001 \mathrm{~ns}$ \\
$\mathrm{CV} \%$ & $7,262^{*}$ & $40,13^{*}$ & 10,9 & 27,2 \\
\hline
\end{tabular}

Teste $\mathrm{F}-\mathrm{ns},{ }^{*} \mathrm{e}^{* *}$ - não significativo e significativo a $5 \%$ e $1 \%$ de probabilidade de erro.

Possivelmente, na ausência de silício, o estresse causado pela deficiência e excesso de $\mathrm{N}$ pode ter influenciado as plantas a investirem em mais folhas, já com a presença do Si o estresse pode ter sido amenizado equiparando os tratamentos. Confirmando com o que Ma et al. (2006b) relatam em seu trabalho, no qual, o estresse causado pelo excesso de $\mathrm{N}$ pode ser amenizado ou até mesmo mitigado com a presença do silício; e com o trabalho de Ferreira et al. (2010), que da mesma maneira, demostrou que a concentração de $\mathrm{N}$ em níveis sub ótimos também podem ser amenizados pela presença do elemento em estudo.

Tabela 4: Efeitos das interações entre silício e formas de nitrogênio para número de folhas totais e número de folhas comerciais. Alta Floresta - MT, 2016.

\begin{tabular}{|c|c|c|c|c|}
\hline \multirow{3}{*}{ Fontes de nitrogênio } & \multicolumn{4}{|l|}{ Silício } \\
\hline & \multicolumn{2}{|c|}{ № folhas totais } & \multicolumn{2}{|c|}{ № folhas comerciais } \\
\hline & $-\mathrm{Si}$ & $+\mathrm{Si}$ & $-\mathrm{Si}$ & $+\mathrm{Si}$ \\
\hline $30 \% \mathrm{~N}-\mathrm{NO}_{3}^{-}$ & $11,80 \mathrm{Aa}$ & $8,80 A b$ & $9,20 \mathrm{Aa}$ & $8,60 A a$ \\
\hline $100 \% \mathrm{~N}^{-\mathrm{NH}_{4}}{ }^{+}$ & $10,20 \mathrm{Aa}$ & $10,40 \mathrm{Aa}$ & $0,00 B C$ & $10,20 \mathrm{Aa}$ \\
\hline $100 \% \mathrm{~N}^{-\mathrm{NO}_{3}}{ }^{-}$ & $7,00 \mathrm{Bb}$ & $9,80 \mathrm{Aa}$ & $4,80 \mathrm{Bb}$ & $9,80 \mathrm{Aa}$ \\
\hline
\end{tabular}

Médias seguidas de mesma letra maiúscula na linha e minúscula na coluna, não diferem entre si, pelo teste de Tukey a $5 \%$ de probabilidade.

O tratamento de $\mathrm{N}$ completo (100\% na forma de nitrato), que teve um aumento no número de folhas totais com a aplicação de Si em relação a não aplicação. Verificou-se, comparando os tratamentos com nitrato nas doses completas e subdose, quando disponibilizado a dose de $\mathrm{N}$ abaixo do necessário para a planta, as respostas passam a ser um decréscimo do número de folhas totais. Como observado por Bybordi (2010), a aplicação de N (formas de nitrato e amônio) com aplicação de Si na cultura do Brassica napus L., proporcionou relação benéfica para o excesso de nitrato $+\mathrm{Si}$, promovendo aumento da produção de massa fresca e área foliar nas plantas.

Ao avaliar o número de folhas comerciais, isento da aplicação do Si, a fonte N (forma de amônio) não apresentou nenhuma folha comercial. Enquanto, o tratamento na fonte de $30 \%$ na forma de nitrato (deficiência) obteve-se maior número de folhas comerciais, diferenciando-se dos demais tratamentos. Comparando com a aplicação de $\mathrm{Si}$, houve diferença na fonte de $100 \% \mathrm{~N}$ (forma de amônio), que na ausência de Si não apresentou folhas comerciais e teve um incremento na presença deste elemento. Este aumento no número de folhas comerciais ocorreu também no tratamento com $100 \%$ de $\mathrm{N}$ (forma de nitrato). Assemelhando-se com o trabalho de Resende (2008), que notou aumento da massa verde comercial e total da alface submetidas a aplicação de Si. 
Quando comparada o número de folhas totais e o número de folhas comerciais, a presença de Si proveu menores prejuízos quando comparado com a sua ausência. Resultado semelhante ao de Ferreira et al. (2010), que avaliando a aplicação de silicato de cálcio em plantas de alface, verificaram a diminuição do número de folhas senescentes e número de folhas doentes. Isso pode ser explicado, pois de acordo com Resende (2008) e Rodrigues et al. (2011), o Si é um elemento chave no fortalecimento da parede celular dos vegetais pois possibilita que o mesmo suporte estresses, sejam eles bióticos ou abióticos. Assim, pode-se notar que a aplicação de Si auxilia nas características exigidas pelo mercado, mesmo quando há déficit ou excesso de nitrogênio na adubação.

Para a variável diâmetro da cabeça (Tabela 5), as formas de N na ausência do Si proporcionaram dois extremos, sendo que o tratamento de $100 \%$ do $\mathrm{N}$ na forma de amônio apresentou um menor diâmetro da cabeça, já o de $30 \%$ de $\mathrm{N}$ na forma de nitrato, teve os maiores diâmetros, e naquele em que $100 \%$ do $\mathrm{N}$ foi na forma de nitrato, os tamanhos foram intermediários. Porém, este último tratamento, quando em conjunto com Si, apresentou incremento no diâmetro da cabeça não diferenciando estatisticamente da subdose de $30 \%$ de $\mathrm{N}$ na forma nítrica.

Tabela 5: Efeitos das interações entre silício e formas de nitrogênio para diâmetro da cabeça e comprimento do caule de plantas de alface. Alta Floresta - MT, 2016.

\begin{tabular}{|c|c|c|c|c|}
\hline \multirow{3}{*}{ Fontes de nitrogênio } & \multicolumn{4}{|l|}{ Silício } \\
\hline & \multicolumn{2}{|c|}{ Diâmetro da cabeça $(\mathrm{cm})$} & \multicolumn{2}{|c|}{ Comprimento do caule $(\mathrm{cm})$} \\
\hline & $-\mathrm{Si}$ & $+\mathrm{Si}$ & $-\mathrm{Si}$ & $+\mathrm{Si}$ \\
\hline $30 \%$ N-NO-3 & $23,00 \mathrm{Aa}$ & $20,60 \mathrm{Aa}$ & $5,80 \mathrm{Aa}$ & $5,78 \mathrm{Aa}$ \\
\hline $100 \% \mathrm{~N}-\mathrm{NH}+4$ & $14,55 \mathrm{Ac}$ & $12,55 \mathrm{Ab}$ & $2,40 \mathrm{Bb}$ & $5,16 \mathrm{Aa}$ \\
\hline $100 \%$ N-NO-3 & $18,10 \mathrm{Bb}$ & $23,70 \mathrm{Aa}$ & $7,55 \mathrm{Aa}$ & $4,80 \mathrm{Ba}$ \\
\hline
\end{tabular}

Médias seguidas de mesma letra maiúscula na linha e minúscula na coluna, não diferem entre si, pelo teste de Tukey a $5 \%$ de probabilidade.

Relacionando ausência e presença de Si dentro de cada fonte, para a variável diâmetro da cabeça, não houve diferença significativas no tratamento $30 \%$ de $\mathrm{N}$ na forma de nitrato e $100 \%$ de $\mathrm{N}$ na forma de amônio. Já a fonte $100 \%$ do $\mathrm{N}$ na forma de nitrato apresentou maior média na presença de Si. Reforçando a importância da aplicação deste nutriente.

A variável comprimento do caule, na ausência de Si, teve as maiores médias nas doses de 30\% e 100\% de $\mathrm{N}$ na forma de nitrato. Isso mostra a influência negativa de doses totais de $\mathrm{N}$ na forma de amônio na ausência de Si. Contudo, quando aplicado o Si não houve diferença entre as formas aplicadas de nitrogênio, mostrando a capacidade do Si em estabilizar os efeitos de estresse ocasionado pela deficiência ou excesso de N. Os valores obtidos com a ausência do silício foram próximos aos valores relatados por Resende et al. (2005), o qual deixa claro que para a altura do caule, os valores considerados ótimos variam entre 6 e $9 \mathrm{~cm}$, sendo que o único tratamento que não atingiu estas medidas foi o $100 \%$ do $\mathrm{N}$ na forma de nitrato, porém sem diferenças significativas dos demais.

Observou-se que, para comprimento de caule, a dose de $30 \%$ de $\mathrm{N}$ na forma de nitrato não apresentou diferenças estatísticas entre a aplicação ou não de Si, diferentemente a dose de $100 \%$ apresentou um decréscimo com o incremento de Si, já a dose em excesso (100\%) e na fonte amônio teve um incremento positivo na aplicação de silício. 


\section{CONCLUSÕES}

De forma geral, $100 \%$ de $\mathrm{N}$ na forma de $\mathrm{NH}_{4}{ }^{+}$apresentou menores médias, evidenciando que o fornecimento total do $\mathrm{N}$ na forma amoniacal é toxico a plantas de alface. Mesmo com algumas variáveis não sendo influenciadas como o acúmulo de massa, para outras importantes variáveis o silício é um fator determinante para o bom desenvolvimento da alface americana, atenuando o estresse decorrente da deficiência ou excesso de $\mathrm{N}$ e melhorando aspectos exigidos comercialmente.

\section{REFERÊNCIAS}

ABCSEM. Associação brasileira do comercio de sementes e mudas. Dados do setor. ABCSEM, 2017.

ABRANTES, F. L.; KULCZYNSKI, S. M.; SORATTO, R. P.; BARBOSA, M. M. M.. Nitrogen top-dressing and the physiological and sanitary quality of proso millet (Panicum miliaceum L.) seeds. Revista Brasileira de Sementes, Brasília, v.32, n.3, p.106-115, 2010. DOI: http://doi.org/10.1590/S0101-31222010000300012

ADLER, P. R.; WILCOX, G. E.; MARKHART, A. H.. Ammonium decreases muskmelon root system hydraulic conductivity. Journal of Plant Nutrition, New York, v.19, p.1395-1403, 1996. DOI: http://doi.org/10.1080/01904169609365207

AGUIAR JÚNIOR, R. A.; GUISCEM, J. M.; SILVA, A. G. P.; FIGUEIREDO, R. T.; CHAVES, A. M.; PAIVA, J. B. P.; SANTOS, F. N.. Interferência de doses de nitrogênio na produção de área foliar, biomassa fresca e seca de rúcula. Horticultura Brasileira, Brasília, v.28, n.2, p.S3970-S3974, 2010.

BRITO, D.T.; SIDDIQI, M. Y.; GLASS, A. D. M.; KRONZUCKER, H. J.. Futile transmembrane $\mathrm{NH}^{+}{ }_{4}$ cycling: a cellular hypothesis to explain ammonium toxicity in plants. Proceedings of the National Academy of Sciences, Manila, v.98, n.7, p.4255-4258, 2001. DOI: http://doi.org/10.1073/pnas.061034698

BYBORDI, A.. Influence of NO3:NH4 ratios and silicon on growth, nitrate reductase activity and fatty acid composition of canola under saline conditions. African Journal of Agricultural Research, Lagos, v.5, n.15, p.1984-1992, 2010. DOI: http://doi.org/10.5897/AJAR09.064

CAMPOS, C. N. S.; PRADO, R. M.; CAIONE, G. LIMA NETO, A. J.; MINGOTTE, F. C.. Silicon and excess ammonium and nitrate in cucumber plants. African Journal of Agricultural Research, Lagos, v.11, n.4, p.276-283, 2016. Dol: http://doi.org/10.5897/AJAR2015.10221

CHEN, L.; LIU, S.; GAI, J.; ZHU, Y.; YANG, L.; WEI, G.. Effects of nitrogen forms on the growth, ascorbate-glutathione cycle and lipid peroxidation in developing seeds of vegetable soybean. African Journal of Agricultural Research, Lagos, v.4, n.11, p.1178-1188, 2009.

DEUNER, C.; BORGES, C. T.; ALMEIDA, A. S.; MENEGHELLO, G. E.; TUNES, L. V. M.. Ácido jasmónico como promotor de resistência em plantas. Revista de Ciências Agrárias, Lisboa, v.38, n.3, p.275-281, 2015.

FAO. World Food and Agriculture. Statistical pocketbook
2019. Rome: FAO, 2019.

FÁTIMA, R. T.; JESUS, E. G.; GUERRERO, A. C.; ROCHA, J. L. A.; BRITO, M. E. B.. Adubação silicatada como atenuante do estresse hídrico no crescimento e trocas gasosas da alface. Engenharia na Agricultura, v.27, n.2, p.170-178, 2019. DOI: http://doi.org/10.13083/reveng.v27i2

FERREIRA, D. F.. Sisvar: A computer statistical analysis system. Ciência e Agrotecnologia, Lavras, v.35, n.6, p.10391042, 2011.

FERREIRA, R. L. F.; SOUZA, R. J.; CARVALHO, J. G.; NETO, S. E. A.; MENDONÇA, V.; WADT, P. G. S.. Avaliação de cultivares de alface adubadas com silicato de cálcio em casa-devegetação. Ciência e Agrotecnologia, Lavras, v.34, n.5, p.1093-1101, 2010. DOI: http://dx.doi.org/10.1590/S141370542010000500003

GUIMARÃES, N. R.; SOUZA, R. F.; SILVA, A. G.; BITTAR, D. Y.. Adubação nitrogenada na produção de rúcula. Ipê Agronomic Journal, v.3, n.2, p.44-55, 2019.

HECKMAN, J.. Silicon: a beneficial substance. Better Crops, v.97, n.4, p.14-16, 2013.

HOAGLAND, D. R.; ARNON, D. I.. The water culture method for growing plants without soils. Berkeley: California Agricultural Experimental Station, 1950.

LEWIS, O. A. M.; LEIDI, E. O.; LIPS, S. H.. Effect of nitrogen source on growth response to salinity stress in maize and wheat. New Phytologyst, Oxford, v.111, p.55-160, 1989.

LIMA FILHO, O. F.; TSAI, S. M.. Crescimento e produção do trigo e da aveia branca suplementados com silício. Embrapa Agropecuária Oeste, 2007.

MA, J. F.; TAMAI, K. YAMAJI, N. MITANI, N. KONISHI, S.; KATSUHARA, M.; ISHIGURO, M. MURATA, Y.; YANO, M.. Silicon transporter in rice. Nature, Londres, v.440, n.7084, p. 688-691, 2006a.

MA, J. F.; YAMAJI, N.. Silicon uptake and accumulation in higher plants. Trends in Plant Science, Amsterdã, v.11, n.8, p.392-397, 2006b. DOI: http://doi.org/10.1016/i.tplants.2006.06.007

MALAVOLTA, E.. Manual de nutrição mineral de plantas. Agronômica Ceres, 2006.

NATHAWAT, N. S, KUHAD, M. S.; GOSWAMI, C. L.; PATEL, A. 
L.; KUMAR, R.. Interactive effects of nitrogen source and salinity on growth indices and ion content of Indian mustard Journal of Plant Nutrition, New York, v.30, p.569-598, 2007. DOI: $\underline{\text { http://doi.org/10.1080/01904160701209329 }}$

RAAB, T. K.; TERRY, N.. Carbon, nitrogen and nutrient interactions in Beta vulgaris $\mathrm{L}$. as influenced by nitrogen source, $\mathrm{NO}_{3}{ }_{3}$ versus $\mathrm{NH}^{+}{ }_{4}$. Plant Physiology, Bethesda, v.107, p.575-584, 1995. DOI: http://doi.org/10.1104/pp.107.2.575

RAAB, T. K.; TERRY, N.. Nitrogen-source regulation of growth and photosynthesis in Beta vulgaris L. Plant Physiology, Bethesda, v.105, p.1159-1166, 1994. DOI: http://doi.org/10.1104/pp.105.4.1159

RESENDE, G. M.. Silício também na alface. Petrolina: Embrapa Semiárido, 2008.

RESENDE, G. M.; YURI, J. E.; CARVALHO, J. G.; SOUZA, R. J.; RODRIGUES JUNIOR, J. C.; MOTA, J. H.. Resposta da alface americana (Lactuca sativa L.) a doses e épocas de aplicação de cobre. Ciência Agrotecnologia, Lavras, v.29, n.6, p.12091214, 2005. DOI: http://doi.org/10.1590/S141370542005000600015

RODRIGUES, F. Á.; OLIVEIRA, L. A.; KORNDORFER, A. P.; KORNDORFER, G. H.. Silício: Um elemento benéfico e importante para as plantas. Informações agronômicas, São Paulo, n.134, 2011.
SALVADOR, J. O.; MOREIRA, A; MURAOKA, T.. Sintomas visuais de deficiências de micronutrientes e composição mineral de folhas em mudas de goiabeira. Pesquisa Agropecuária Brasileira, Brasília, v.34, n.9, p.1655-1662, 1999. DOI: http://doi.org/10.1590/S0100204X1999000900016

SANTOS, D.; MENDONÇA, R. M. N.; SILVA, S. M.; ESPÍNOLA, J.E. F.; SOUZA, A. P.. Produção comercial de cultivares de alface em Bananeiras. Horticultura Brasileira, Vitoria da Conquista, v.29, n.4, p.609-612, 2011. DOI: http://doi.org/10.1590/S0102-05362011000400028

SCHRADER, L. E.. Functions and translocations of nitrogen in higher plants. In: SILVA JÚNIOR, G. B.. Relação amônio e nitrato, mitigação da toxicidade amoniacal com silício e curva de acúmulo de nutrientes em mudas de maracujazeiro. Tese (Doutorado) - Universidade Estadual Paulista Júlio de Mesquita Filho, São Paulo, 2015.

WALCH-LIU, P.; NEUMANN, G.; BANGERTH, F.; ENGELS, C.. Rapid effects of nitrogen form on leaf morphogenesis in tobacco. Journal of Experimental Botany, Oxford v.51, p.227-237, 2000.

ZHANG, W.; XIE, Z.; LANG, D.; CUI, J.; ZHANG, X.. Beneficial effects of silicon on abiotic stress tolerance in legumes. Journal of Plant Nutrition, v40, n.15, p.2224-2236, 2017. DOI: http://doi.org/10.1080/01904167.2017.1346127

A CBPC - Companhia Brasileira de Produção Científica (CNPJ: 11.221.422/0001-03) detém os direitos materiais desta publicação. Os direitos referem-se à publicação do trabalho em qualquer parte do mundo, incluindo os direitos às renovações, expansões e disseminações da contribuição, bem como outros direitos subsidiários. Todos os trabalhos publicados eletronicamente poderão posteriormente ser publicados em coletâneas impressas sob coordenação da Sustenere Publishing, da Companhia Brasileira de Produção Científica e seus parceiros autorizados. Os (as) autores (as) preservam os direitos autorais, mas não têm permissão para a publicação da contribuição em outro meio, impresso ou digital, em português ou em tradução. 